Article

\title{
The European Media Portrayal of Climate Change: Implications for the Social Mobilization towards Climate Action
}

\author{
Alexandre O. Tavares ${ }^{1}{ }^{(0}$, Neide P. Areia ${ }^{2, *}$, Sinead Mellett ${ }^{3}{ }^{\complement}$, Julia James ${ }^{4}{ }^{\circledR}$, \\ Diego S. Intrigliolo ${ }^{5}$, Laurence B. Couldrick ${ }^{6}$ and Jean-François Berthoumieu ${ }^{4}$ \\ 1 Centre for Social Studies, Department of Earth Sciences, Faculty of Sciences and Technology, \\ University of Coimbra, 3030-790 Coimbra, Portugal; atavares@ci.uc.pt \\ 2 Centre for Social Studies, University of Coimbra, Colégio de S. Jerónimo, Apartado 3087, \\ 3000-995 Coimbra, Portugal \\ 3 Bioscience Research Institute, Athlone Institute of Technology, Dublin Road, Athlone, \\ Co. N37 HD68 Westmeath, Ireland; smellett@ait.ie \\ 4 Association Climatologique de la Moyenne Garonne, Aérodrome Garenne, 47310 Estillac, France; \\ juliajames.riskaquasoil@orange.fr (J.J.); acmg@acmg.asso.fr (J.-F.B.) \\ 5 Department Riego. Centro de Edafología y Biología Aplicada del Segura (CEBAS-CSIC), \\ Campus Universitario de Espinardo, PO Box 164, CP 30100 Murcia, Spain; dintri@cebas.csic.es \\ 6 Westcountry Rivers Trust, Rain-Charm House, Kyl Cober Parc, Stoke Climsland, Cornwall PL17 8PY, UK; \\ laurence@wrt.org.uk \\ * Correspondence: neideareia@ces.uc.pt
}

Received: 26 August 2020; Accepted: 30 September 2020; Published: 9 October 2020

check for updates

\begin{abstract}
Beyond other social actors, such as policymakers and scholars, common citizens are also expected to actively engage with climate change, by adopting sustainable actions and supporting environmental policies. However, and despite the actual growing of environment-related social movements, a kind of inertia still prevails in the social climate of our society. The media should play a key role in promoting, among common individuals, the adoption of new and more sustainable practices. However, it is argued that the media seems to be failing to effectively address the climate crisis. As such, this study aims to identify the main weaknesses of climate change media communication to further discuss possible opportunities of communication improvements. For that, 1609 news articles published between 2017 and 2018 in five European countries were analyzed in-depth, through quantitative content analysis. The news' general characteristics, specifically reported themes, and the specificities of actors' discourses were taken into account for the analysis. It was verified that the European media tends to report climate change by using distant (e.g., future-focused) and outcome (e.g., threatening messages) framings, based on non-resilient, scientific, and political narratives, whilst overlooking the role of civil society on adapting to climate change. These results demonstrate that instead of promoting society's climate action, the media may be contributing to a widespread social apathy about the climate and the disengagement of individuals regarding environment-related matters. Evidence-based forms of improving the media's communication on climate change will be further discussed.
\end{abstract}

Keywords: climate change; media; communication; social inertia; climate action

\section{Introduction}

Climate change is arguably the most threatening and urgent transnational challenge of our times, demanding public attention and action [1]. The actual climate crisis is pushing several research sectors 
and activity to rapidly develop and implement innovative forms of mitigating and adapting to the climate challenge. Several societal spheres, including common individuals, are called upon to adopt new ways of thinking and behaving in order to adapt to climate change [2,3].

We are now witnessing a growth of social movements pressing for a political climate change response [4,5]. Yet, one can argue that these social movements may be effective in raising awareness to the actual climate crisis but ineffective in driving a real social change with individuals actively engaging with environment-related issues. Indeed, it has been proven that a social inertia concerning climate still prevails in our society, constraining the development and implementation of effective measures to address climate change [6].

Media may play a crucial role in mitigating the actual social inertia about climate [7]. Indeed, it is well known that the media, as the primary source of information for common citizens, plays a key role in shaping and affecting public understanding and engagement to climate change [8,9]. In recent years, a large body of literature has been emerging in which studies on media representations of climate change, the salience of climate change frames in news coverage, and the influence of the media narratives and framing of climate change on public attitudes and behavior toward climate science and environmental policies are particularly prominent $[10,11]$. On the latter, and just to mention a few examples, it has been proved that uncertainty frames tend to confuse lay audiences about the state of environmental science and reduce the public's propensity to engage with climate change [12]. The same tends to occur when media narratives focus on the economic cost of climate mitigation actions [13]. Contrarily, avoiding environmental hyperopia forms of reporting climate change (e.g., distant framing) by giving salience to temporal and spatial proximity narratives is proven to be related with the public's heightened awareness and engagement to the actual environmental emergency [14,15]. However, despite the growing evidence on appropriate and effective forms of communicating climate change to the lay public, and the acknowledgment of the media's influential role for audiences' understanding and action, the media has been failing to effectively convey information on climate change and thus become a key contributor to a societal change for sustainability [1].

This exploratory study deals with the media's failure to convey effective climate change messages to civil society. Specifically, it aims to identify the main weaknesses of climate change media communication to further discuss possible opportunities for improvements in communication. For that, an in-depth quantitative content analysis $[16,17]$ was conducted concerning climate change media coverage produced in five European countries, considering the news articles' general characteristics, specific reported themes, and the specificities of actors' discourses. Through this, media communication weaknesses will be identified and further discussed in contrast with alternative forms of communicating climate change.

\section{Methods}

This study encompassed the detailed analysis of the climate change media coverage in five European countries. Specifically, three Mediterranean countries-France, Portugal, and Spain - and two northern European countries-Ireland and the United Kingdom. The study follows a similar research design employed in previous studies on the same topic of research $[7,10,14,18]$ and was conducted through four main sequential phases: (1) establishment of a research equation, (2) definition of a time frame, (3) selection of most relevant news, and (4) quantitative content analysis. Each study phase is further described below.

\subsection{Establishment of the Research Equation}

The same research equation was first formulated in English and then translated into French, Portuguese, and Spanish. In English, it reads as follows: (climate change *) AND (risk * OR water * OR soil *). The defined research equation was further entered into the Google News search engine. 


\subsection{Definition of a Time Frame}

Six time frames were set for the years 2017 and 2018, as follows: (1) February 1st, 2017-March 31st, 2017; (2) June 1st, 2017-July 31st, 2017; (3) October 1st, 2017-November 30th, 2017; (4) February 1st, 2018-March 31st, 2018; (5) June 1st, 2018-July 31st, 2018; (6) October 1st, 2018-November 30th, 2018. These time frames were established in order to ensure the selection of relevant news from different periods of the year.

\subsection{Selection of the Most Relevant News}

The selection of news was conducted for the countries involved independently. The established research equation was entered into the Google News search engine repeatedly for each of the six time frames. For each time frame, an average of 60 news articles was selected, according to the defined quota suggested in previous studies [7].

The first screening of the news articles was conducted by considering their relevance for this study. For the screening, a preliminary reading of each article was conducted, mainly considering the title and the news lead, that is, the opening paragraph of the article. News articles were not selected when they were not clearly related to climate change and/or environmental matters.

Subsequently, an in-depth and detailed reading of the previously selected articles was conducted to exclude the existence of duplicated pieces and to eliminate the ones that did not exactly cover climate change-related topics.

\subsection{Quantitative Content Analysis}

The method employed to analyze the gathered data was a quantitative content analysis [16]. A standardized codebook was developed based on Areia et al. (2019) [7], to further code the obtained content systematically, considering two types of variables: (1) news' characteristics; and (2) specific themes. News' general characteristics included: publishing period, according to the six pre-defined time frames; type of newspaper; geographical focus; actors involved; and type of knowledge in which actors' narratives are based on. News' specific themes include: main hazardous processes; event's timing; risk management action; climate change adaptation measures; and main sector.

The first set of analyses encompassed the prevalent study of news' characteristics and specific themes. Category prevalence was determined through frequency statistics. The second set of analyses encompassed a closer analysis of actors' discourse, namely researchers, policymakers, managers, and the general public. For each actors' subsample, the prevalence of news' characteristics and specific themes was determined through frequency statistics. To further understand the strength and direction of association between actors' discourse and preferred reporting themes, a correlational study was performed, using Pearson product-moment correlation coefficient, or when assumptions of the Pearson correlation were markedly violated, its nonparametric equivalent, the Spearman's rank correlation coefficient.

All statistical analysis was performed using IBM SPSS Statistics, version 22.

\section{Results}

The presentation of results will encompass: (i) prevalence studies regarding news' general characteristics and specific themes regarding the whole sample and country of origin; and (ii) prevalence and correlational studies regarding news' general characteristics and specific themes according to each actors' narratives.

Conventionally, when displaying prevalence results, $N$ refers to the full sample, while $n$ is related to the subsamples (specific countries in Section 3.1 and specific actors in Section 3.2). 


\subsection{News' Characteristics and Specific Themes: Prevalence Studies}

A total of 1609 news articles were selected from France $(n=266,16.5 \%)$, Ireland $(n=297$, $18.5 \%)$, Portugal $(n=341,21.2 \%)$, Spain $(n=348,21.6 \%)$ and The United Kingdom $(n=357,22.2 \%)$. A consistent number of news from each of the six defined publishing periods was collected for the five countries $(\approx n=50-60)$ (see Supplementary Materials). The vast majority of the news encountered were published in national newspapers ( $n=1486,92.4 \%)$, such as Le Monde (France), The Irish Times (Ireland), Público (Portugal), El País (Spain), and The Guardian (United Kingdom).

In general, European media tends to cover non-national climate change-related events $(N=1125$, $69.9 \%)$. France $(n=108,40.6 \%)$ and the United Kingdom $(n=96,26.9 \%)$ tend to privilege global framings, while Portugal $(n=169,49.6 \%)$ and Spain $(n=159,45.7 \%)$ privilege national framings. Interestingly, North American $(N=251,15.6 \%)$ events are more frequently covered in the European media than other European countries $(N=215,13.4 \%)$-different from the news' country of origin-events.

With the exception of Portugal, that gives more salience to the managers' narrative $(n=126$, $37.0 \%)$; the other four countries privilege the researchers discourse. For that reason, almost a half of the European news focuses on researchers' discourse $(N=650,40.4 \%)$, followed by policy makers' discourse $(N=412,25.6 \%)$. Regarding the type of knowledge, the scientific $(N=613,38.2 \%)$ seems to be preferred by the European press.

Regarding news' specific themes, the European press tend not to mention any hazardous processes $(N=408,25.4 \%)$ in its news articles, which also holds true for the Portuguese $(n=105,30.8 \%)$, Spanish $(n=132,37.9 \%)$, and British $(n=166,46.5 \%)$ press. Differently, in both French $(n=93,35.0 \%)$ and Irish media $(n=148,49.8 \%)$, significant salience is given to extreme meteorological conditions. Current events $(N=1232,76.6 \%)$ are the most covered by the European media, followed by predictable events $(N=275,17.1 \%)$.

With regard to risk management actions, it is noteworthy that almost a half of the European news pieces do not mention any specific action $(N=654,40.6 \%)$. With exception for the Irish press, which more frequently mentions impact reduction or mitigation actions $(n=225,75.8 \%)$, the remaining countries follow the European press by hardly mentioning any risk management action.

A similar panorama was found for the adaptation measures, as the European press tends to mention no specific adaptation measure $(N=656,40.8 \%)$. Only in Ireland, is a high salience given to a specific adaptation measure, particularly for measures regarding the reduction in economic loss $(n=138,46.5 \%)$.

Finally, European news tend to focus on several sectors in a same news' article ( $N=418,26.0 \%)$. This is also true for the majority of the analyzed countries.

Table 1 displays the detailed results of the prevalence studies regarding news' characteristics and specific themes for both the whole sample and countries' subsamples. 
Table 1. Results of prevalence studies regarding news' characteristics and specific themes.

\begin{tabular}{|c|c|c|c|c|c|c|}
\hline & Total N (\%) & FR $N(\%)$ & IR N (\%) & PT N (\%) & SP N (\%) & UK $N(\%)$ \\
\hline \multicolumn{7}{|l|}{ News' Characteristics } \\
\hline \multicolumn{7}{|l|}{ Newspaper } \\
\hline National & $1486(92.4)$ & $228(85.7)$ & $256(86.2)$ & $321(94.1)$ & $326(93.7)$ & $355(99.4)$ \\
\hline Regional & $123(7.6)$ & $38(14.3)$ & $41(13.8)$ & $20(5.9)$ & $22(6.3)$ & $2(0.6)$ \\
\hline \multicolumn{7}{|l|}{ Geographical Focus } \\
\hline Global & $421(26.2)$ & $108(40.6)$ & $50(16.8)$ & $81(23.8)$ & $86(24.7)$ & $96(26.9)$ \\
\hline National & $484(30.1)$ & $75(28.2)$ & $1(0.3)$ & $169(49.6)$ & $159(45.7)$ & $80(22.4)$ \\
\hline Europe & $215(13.4)$ & $27(10.2)$ & $89(30.0)$ & $29(8.5)$ & $44(12.6)$ & $26(7.3)$ \\
\hline North America ${ }^{1}$ & $251(15.6)$ & $21(7.9)$ & $113(38.0)$ & $30(8.8)$ & $13(3.7)$ & $74(20.7)$ \\
\hline Latin America & $47(2.9)$ & $4(1.5)$ & $3(1.0)$ & $8(2.3)$ & $22(6.3)$ & $10(2.8)$ \\
\hline Africa & $96(6.0)$ & $16(6.0)$ & $17(5.7)$ & $16(4.7)$ & $12(3.4)$ & $35(9.8)$ \\
\hline Asia & $52(3.2)$ & $10(3.8)$ & $8(2.7)$ & $2(0.6)$ & $7(2.0)$ & $25(7.0)$ \\
\hline Oceania & $33(2.1)$ & $3(1.1)$ & $16(5.4)$ & $2(0.6)$ & $2(0.6)$ & $10(2.8)$ \\
\hline Antarctica & $10(0.6)$ & $2(0.8)$ & - & $4(1.2)$ & $3(0.9)$ & $1(0.3)$ \\
\hline \multicolumn{7}{|l|}{ Actors Involved } \\
\hline Policymakers & $412(26.6)$ & $65(24.4)$ & $88(29.6)$ & $104(30.5)$ & $89(25.6)$ & $66(18.5)$ \\
\hline Researchers & $650(40.4)$ & $162(60.9)$ & $164(55.2)$ & $87(25.5)$ & $112(32.2)$ & $125(35.0)$ \\
\hline Managers & $390(24.2)$ & $17(6.4)$ & $14(4.7)$ & $126(37.0)$ & $109(31.3)$ & $124(34.7)$ \\
\hline General Public & $157(9.8)$ & $22(8.3)$ & $31(10.4)$ & $24(7.0)$ & $38(10.9)$ & $42(11.8)$ \\
\hline \multicolumn{7}{|l|}{ Type of Knowledge } \\
\hline Technical & $410(25.5)$ & 37 (13.9) & $17(5.7)$ & $130(38.1)$ & $109(31.3)$ & $117(32.8)$ \\
\hline Scientific & $613(38.2)$ & $131(49.2)$ & $146(49.0)$ & $93(27.3)$ & $117(33.6)$ & $126(35.3)$ \\
\hline Non-expert & $144(8.9)$ & $21(7.9)$ & $33(11.1)$ & $22(6.5)$ & $30(8.6)$ & $38(10.6)$ \\
\hline $\begin{array}{l}\text { Policy making-related } \\
\text { Specific themes }\end{array}$ & $442(27.5)$ & $77(28.9)$ & $101(34.1)$ & $96(28.2)$ & $92(26.4)$ & $76(21.3)$ \\
\hline \multicolumn{7}{|l|}{ Hazardous Processes } \\
\hline Drought & $392(24.4)$ & $90(33.8)$ & $46(15.5)$ & $90(26.4)$ & $99(28.4)$ & \\
\hline Forest fires & $42(2.6)$ & $7(2.6)$ & $2(0.7)$ & $28(8.2)$ & $5(1.4)$ & $67(18.8)$ \\
\hline Coastal threats & $89(5.5)$ & $12(4.5)$ & $7(2.4)$ & $23(6.7)$ & $17(4.9)$ & - \\
\hline Extreme meteorological conditions & $363(22.6)$ & $93(35.0)$ & $148(49.8)$ & $39(11.4)$ & $51(14.7)$ & $30(8.4)$ \\
\hline Floods & $37(2.3)$ & $13(4.9)$ & $9(3.0)$ & $3(0.9)$ & $3(0.9)$ & $32(9.0)$ \\
\hline Winds/tornados & $5(0.3)$ & $3(1.1)$ & - & $1(0.3)$ & - & $9(2.5)$ \\
\hline Landslides & $15(0.9)$ & - & $14(4.7)$ & - & $1(0.3)$ & - \\
\hline Unspecified/various & $258(16.0)$ & $43(16.2)$ & $71(23.9)$ & $52(15.2)$ & $40(11.5)$ & - \\
\hline None & $408(25.4)$ & $5(1.9)$ & - & $105(30.8)$ & $132(37.9)$ & $52(14.6)$ \\
\hline Event's Timing & & & & & & $166(46.5)$ \\
\hline Present & $1232(76.6)$ & $193(72.6)$ & $240(80.8)$ & $261(76.5)$ & $269(77.3)$ & \\
\hline Potential & $102(6.3)$ & $35(13.2)$ & $37(12.5)$ & $14(4.1)$ & $14(4.0)$ & $269(75.4)$ \\
\hline Predictable & $275(17.1)$ & $38(14.3)$ & $20(6.7)$ & $66(19.4)$ & $65(18.7)$ & $2(0.6)$ \\
\hline Risk Management & & & & & & $86(24.1)$ \\
\hline Mitigation & $539(33.5)$ & $42(15.8)$ & $225(75.8)$ & $102(29.9)$ & $117(33.6)$ & \\
\hline Alert & $222(13.8)$ & $28(10.5)$ & $4(1.3)$ & $36(10.6)$ & $65(18.7)$ & $53(14.8)$ \\
\hline Reactive/Emergency & $115(7.1)$ & $49(18.4)$ & $14(4.7)$ & $27(7.9)$ & $16(4.6)$ & $89(24.9)$ \\
\hline Preventive & $79(4.9)$ & $16(6.0)$ & $11(3.7)$ & $31(9.1)$ & $9(2.6)$ & $9(2.5)$ \\
\hline None & $654(40.6)$ & $131(49.2)$ & $43(14.5)$ & $145(42.5)$ & $141(40.5)$ & $12(3.4)$ \\
\hline Adaptation Measures & & & & & & $194(54.3)$ \\
\hline Prevention of environmental degradation & $421(26.2)$ & $60(22.6)$ & $95(32.0)$ & $96(28.2)$ & $110(31.6)$ & \\
\hline Access to goods and services & $157(9.8)$ & $12(4.5)$ & $9(3.0)$ & $50(17.4)$ & $68(19.5)$ & $60(16.8)$ \\
\hline Security of people and belongings & $132(8.2)$ & $33(12.4)$ & $17(5.7)$ & $38(11.1)$ & $32(9.2)$ & $18(5.0)$ \\
\hline Reduction in economic loss & $243(15.1)$ & $29(10.9)$ & $138(46.5)$ & $35(10.3)$ & $18(5.2)$ & $12(3.4)$ \\
\hline None & $656(40.8)$ & $132(49.6)$ & $38(12.8)$ & $122(35.8)$ & $120(34.5)$ & $23(6.4)$ \\
\hline Main Sector & & & & & & $244(68.3)$ \\
\hline Agriculture & $378(23.5)$ & $49(18.4)$ & $148(49.8)$ & $59(17.3)$ & $72(20.7)$ & \\
\hline Forestry & $63(3.9)$ & $8(3.0)$ & $14(4.7)$ & $26(7.6)$ & $8(2.3)$ & $50(14.0)$ \\
\hline Human Health & $91(5.7)$ & $23(8.6)$ & $15(5.1)$ & $22(6.5)$ & $22(6.3)$ & $7(2.0)$ \\
\hline Energy & $36(2.2)$ & $3(1.1)$ & - & $13(3.8)$ & $14(4.0)$ & $9(2.5)$ \\
\hline Biodiversity & $103(6.4)$ & $37(13.9)$ & $6(2.0)$ & $17(5.0)$ & $19(5.5)$ & $6(1.7)$ \\
\hline Economy & $101(6.3)$ & $12(4.5)$ & $15(5.1)$ & $14(4.1)$ & $21(6.0)$ & $24(6.7)$ \\
\hline Human Security & $89(5.5)$ & $22(8.3)$ & $4(1.3)$ & $10(2.9)$ & $23(6.6)$ & 39 (10.9) \\
\hline Transports and communication & $13(0.8)$ & $3(1.1)$ & - & $3(0.9)$ & $2(0.6)$ & $30(8.4)$ \\
\hline Coastal areas and sea & $115(7.1)$ & $15(5.6)$ & $7(2.4)$ & $27(7.9)$ & $21(6.0)$ & $5(1.4)$ \\
\hline Various & $418(26.0)$ & $87(32.7)$ & $88(29.6)$ & $78(22.9)$ & $81(23.3)$ & $45(12.6)$ \\
\hline \multirow[t]{2}{*}{ None } & $202(12.6)$ & $7(2.6)$ & - & $72(21.1)$ & $65(18.7)$ & $84(23.5)$ \\
\hline & & & & & $65(18.7)$ & $58(16.2)$ \\
\hline
\end{tabular}

${ }^{1}$ Without Mexico. Legend: FR: France; IR: Ireland; PT: Portugal; SP: Spain; UK: United Kingdom.

\subsection{Actors' Discourse: Prevalence and Correlational Studies}

As discussed in the previous prevalence studies (cf. 3.1), the European climate change media coverage tend to privilege the discourse of researchers $(n=650,40.4 \%)$, followed by policymakers 
( $n=412,25.6 \%)$ and managers $(n=390,24.2 \%)$. The general public $(n=157,9.8 \%)$ is barely mentioned in the European press, accounting for about only $10 \%$ of the whole European news sample.

Table 2 details the results of the prevalence studies regarding news' characteristics and specific themes according to each actors' narratives. Figure 1 summarizes the results obtained by the correlational studies between the actors and news' characteristics and specific themes, while the full correlational matrix is provided in the Supplementary Materials.

Table 2. Results of prevalence studies regarding news' characteristics and specific themes according to each actors' narratives.

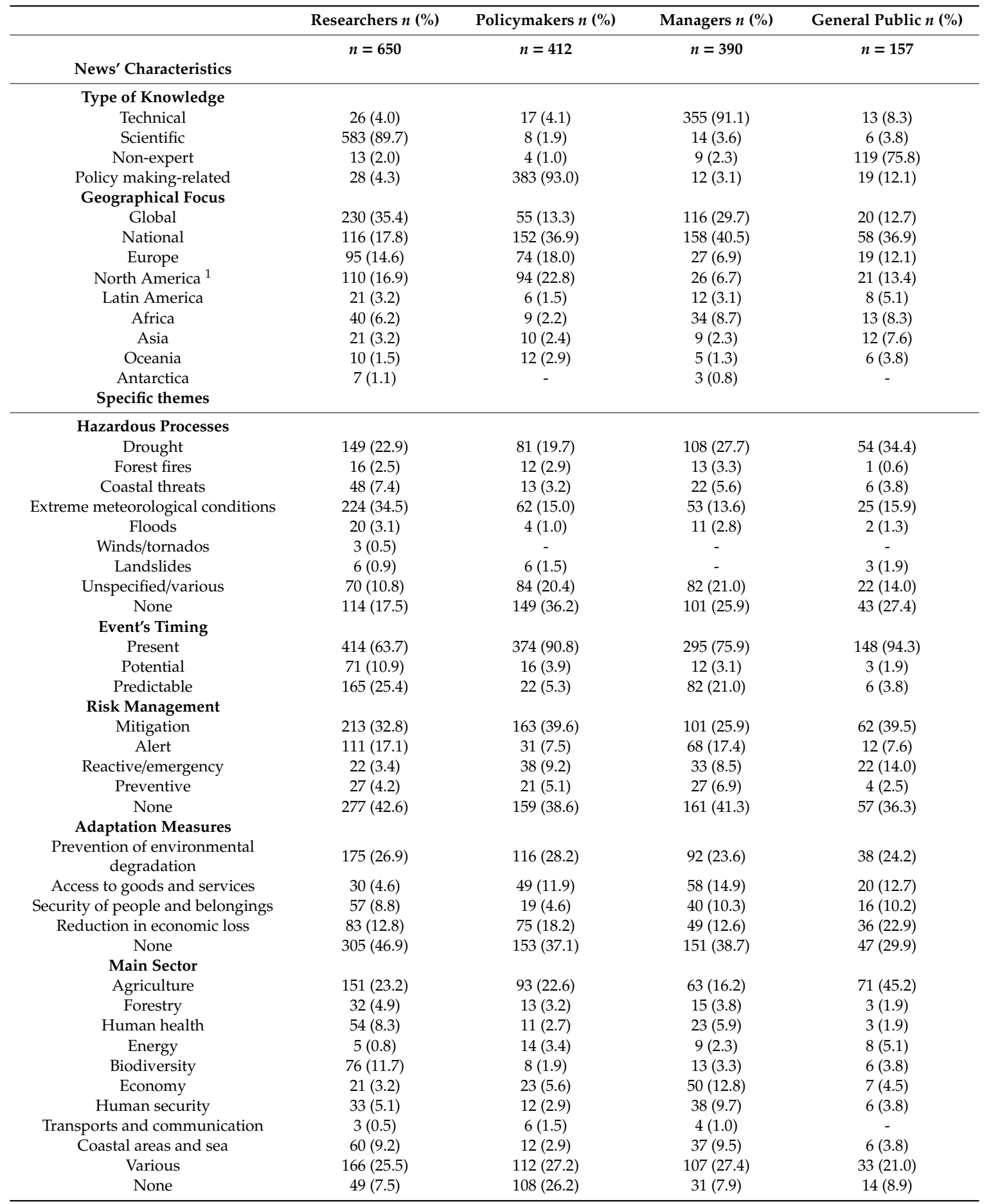

${ }^{1}$ Without Mexico. 


\begin{tabular}{|c|c|c|c|c|c|c|c|c|c|}
\hline & Mn & PM & Rs & GP & & Mn & PM & Rs & GP \\
\hline Knowledge & & & & & \multicolumn{5}{|l|}{ Adaptation Measures } \\
\hline Technical & $* * *$ & $* * *$ & $* * *$ & $* * *$ & \multicolumn{2}{|l|}{ Prevention of environmental degradation } & & & \\
\hline Academic & $* * *$ & $* * *$ & $* * *$ & $* * *$ & Access to goods and services & $* * *$ & & $* * *$ & \\
\hline Non-expert & & $* * *$ & $* * *$ & $* * *$ & \multicolumn{2}{|l|}{ Security of people and belongings } & ** & & \\
\hline Policy-exclusive & $* * *$ & $* * *$ & $* * *$ & $* * *$ & \multicolumn{2}{|l|}{ Reduction of economic loss } & * & * & ** \\
\hline Context & & & & & \multicolumn{2}{|l|}{ None } & & $* * *$ & ** \\
\hline Global & & $* * *$ & $* * *$ & $* * *$ & \multicolumn{5}{|l|}{ Main Sector } \\
\hline National & $* * *$ & $* * *$ & $* * *$ & * & Agriculture & $* * *$ & & & $* * *$ \\
\hline Europe & $* * *$ & ** & & & \multicolumn{5}{|l|}{ Forestry } \\
\hline North America & $* * *$ & $* * *$ & & & \multicolumn{2}{|l|}{ Human Health } & ** & $* * *$ & * \\
\hline Latin America & & * & & & \multicolumn{2}{|l|}{ Energy } & & ** & $* *$ \\
\hline Africa & $* *$ & $* * *$ & & & Biodiversity & ** & $* * *$ & $* * *$ & \\
\hline Asia & & & & $* *$ & Economy & $* * *$ & & $* * *$ & \\
\hline Oceania & & & & & Human Security & $* * *$ & *** & & \\
\hline Antarctica & & & & & \multicolumn{5}{|l|}{ Transports \& Communication } \\
\hline Hazard & & & & & Coastal areas and Sea & * & $* * *$ & $* *$ & \\
\hline Drought & & $* *$ & & ** & \multicolumn{5}{|l|}{ Various } \\
\hline Forest fires & & & & & \multirow[t]{7}{*}{ None } & ** & $* * *$ & $* * *$ & $* * *$ \\
\hline Coastal threats & & $* *$ & ** & & & & & & \\
\hline Extreme meteorological conditions & $* * *$ & $* * *$ & $* * *$ & * & & & & & \\
\hline Floods & & * & & & & & & & \\
\hline \multicolumn{9}{|l|}{ Winds/Tornados } & \\
\hline Landslides & * & & & & & & & & \\
\hline Unspecified/Various & * & * & $* * *$ & & & & & & \\
\hline None & & $* * *$ & $* * *$ & & \multicolumn{5}{|l|}{ Legend } \\
\hline Event's Timing & & & & & Pearson correlation (strength and direction) & & \multicolumn{3}{|c|}{ Actors } \\
\hline Present & & $* * *$ & $* * *$ & $* * *$ & High positive correlation & & Mn & \multicolumn{2}{|c|}{ Managers } \\
\hline Potential & * & * & $* * *$ & * & Moderate positive correlation & & PM & \multicolumn{2}{|c|}{ Policy Makers } \\
\hline Predictable & * & $* * *$ & $* * *$ & $* * *$ & Low positive correlation & & Rs & \multicolumn{2}{|c|}{ Researchers } \\
\hline Risk Management & & & & & Negligible positive correlation & & GP & \multicolumn{2}{|c|}{ General Public } \\
\hline Mitigation & $* * *$ & ** & & & Negligible negative correlation & & & & \\
\hline Alert & * & $* * *$ & $* *$ & * & Low negative correlation & & \multicolumn{3}{|c|}{ Significant level } \\
\hline Reactive/ Emergency & & & $* * *$ & $* * *$ & Moderate negative correlation & & \multicolumn{3}{|c|}{$* p<0.05$} \\
\hline Preventive & * & & & & High negative correlation & & \multicolumn{3}{|c|}{$* p<0.01$} \\
\hline None & & & & & & & \multicolumn{3}{|c|}{$* * p<0.001$} \\
\hline
\end{tabular}

Figure 1. Summary of the correlational studies between the actors and news' characteristics and specific themes.

Regarding researchers' discourse in the European media, it privileges the scientific knowledge ( $n=583,89.7 \%$ ) with which it shows a significant strong positive correlation $(r=0.88, p<0.001)$. Significant weak-to-moderate negative correlations $(r=-0.20-0.43, p<0.001)$ were found between researchers' discourse and the other types of knowledge. Researchers more frequently report global climate change matters $(n=230,35.4 \%), r=0.17, p<0.001$. With regard to the hazardous processes, researchers more frequently address extreme meteorological conditions $(n=224,34.5 \%), r=0.23$, $p<0.001$ and seem to choose a specific hazardous process for which to give salience. This is because a significant negative correlations were found between researchers and the mentioning of various $(r=-0.12, p<0.001)$ or any $(r=-0.15, p<0.001)$ hazardous process. Despite the fact that researchers report present events more frequently $(n=414,63.7 \%)$, significant positive correlations were found between potential $(r=0.16, p<0.001)$ and predictable $(r=0.18, p<0.001)$ events, which indicate that researchers seem to frame their narratives on future events. Researchers tend not to mention any risk management action $(n=277,42.6 \%)$ and the significant correlations encountered with some of the risk management actions, particularly alert and reactive/emergency, were negligible and weak, 
correspondingly. Regarding the adaptation measures, researchers tend not to mention any measure $(n=305,46.9 \%), r=0.10, p<0.001$. Researchers' discourse tends to focus on diverse sectors in a same news' article $(n=166,25.5 \%)$. However, significant positive correlations were found with the biodiversity $(r=0.18, p<0.001)$ and human health $(r=0.10, p<0.001)$ sectors.

Policymakers' discourse is more frequently based on policy-exclusive knowledge ( $n=383,93.0 \%$ ), $r=0.86, p<0.001$. Indeed, other forms of knowledge seem to be neglected in policymakers' narratives, as significant weak-to-moderate negative correlations were found with technical $(r=-0.29, p<0.001)$, scientific $(r=-0.44, p<0.001)$, and non-expert $(r=-0.16, p<0.001)$ knowledge. Policymakers' narratives are tendentiously related to present events $(n=374,90.8 \%), r=0.20, p<0.001$, and are frequently grounded on non-national events $(n=260,63.1 \%)$, and a significant positive correlation was found between North American events $(r=0.12, p<0.001)$. On policymakers' discourses, there is a tendency to mention neither any hazardous process $(n=149,36.2 \%), r=0.18, p<0.001$, nor risk management actions $(n=159,28.6 \%)$ or adaptation measures $(n=153,37.1 \%)$. Similarly, policymakers' discourses tend not to focus on a specific sector, by mentioning various in a same news article $(n=112$, $27.2 \%)$ or none $(n=108,26.2 \%)$, showing, with this last category, a significant positive correlation, $r=0.24, p<0.001$.

On the European media, managers' narratives are clearly framed in technical knowledge $(n=355$, 91.1\%), with which a significant strong correlation was found, $r=0.85, p<0.001$. Other forms of knowledge, such as the scientific $(r=-0.40, p<0.001)$, non-expert $(r=-0.31, p<0.001)$ and policy making-related $(r=-0.13, p<0.001)$ seem to be exempted from managers' discourse. Managers' tend to focus on non-national $(n=232,59.5 \%), r=0.13, p<0.001$, and present events $(n=295,75.9 \%)$. Although the drought $(n=108,27.7 \%)$ was the most frequent hazardous process mentioned in managers' discourse, a significant correlation with it was not found. Contrarily, a negative significant correlation was found between managers' discourse and extreme meteorological conditions, $r=-0.12, p<0.001$. Without showing significant correlations with these categories, managers' discourse tends not to refer to neither any risk management action $(n=161,41.3 \%)$, nor any adaptation measure $(n=151,38.7 \%)$. Still, regarding adaptation measures, a significant moderate positive correlation was found between managers' discourse and adaptation measures aiming to guarantee the citizens' access to goods and services, $r=0.10, p<0.001$. Although in managers' discourse, several sectors are most frequently covered in the same news article $(n=107,27.4 \%)$, it is with the economical $(r=0.15, p<0.001)$ and human security sectors $(r=0.10, p<0.001)$ that managers' discourse is positively correlated.

Finally, the discourse of the general public is based on non-expert knowledge ( $n=119,75.8 \%)$, confirmed by a significant strong positive correlation, $r=0.77, p<0.001$. Significant negative correlations were found between the general public's discourse, with the remaining forms of knowledge. The general public tends to focus its narratives on national $(n=58,36.9 \%), r=0.05, p=0.04$, and present $(n=148$, $94.3 \%), r=0.14, p<0.001$, events. Drought $(n=54,34.4 \%), r=0.08, p=0.02$, is the main hazardous process mentioned in the general public's discourse. In spite of the fact that no significant correlations were found, the general public tend to mention more frequently the impact reduction/mitigation actions $(n=62,39.5 \%)$. Regarding adaption measures, the general public's discourse follows the other actors' tendency, by tending not to mention any adaptation measure $(n=47,29.9 \%)$. However, a significant positive correlation was found between measures aiming to reduce economic loss, $r=0.07, p=0.004$. The most frequent sector mentioned in the general public's discourse is agriculture $(n=71,45.2 \%)$, with which a significant positive correlation was found, $r=0.17, p<0.001$. It is worth mentioning that the general public's discourse seems to generally focus on a specific sector, as a significant negative correlation was ascertained without mentioning any sector, $r=-0.36, p=0.02$.

\section{Discussions}

The current climate emergency is pushing environment-related actors to develop innovative ways of actively engaging the civil society with climate change [19] and thus produce a sustainable behavior transformation in individuals. Without doubt, media is a key contributor to shaping public perceptions, 
attitudes, and action regarding environmental issues [20,21]. Indeed, media is considered a mediator between the produced climate science and lay knowledge and, thus, is now called to improve its communication of climate change in order to promote individuals' climate action [7]. However, up to this point in time, the media seems to be failing to properly educate and engage citizens with climate change [1], thus contributing to society's climate inertia.

As such, this study comes to identify the major weaknesses in the media's climate change communication in five European countries, to further discuss possible strategies to overcome the actual inefficient communication praxis. In order to summarize the main findings of this study, a conceptualization of the media's discourses on climate change is provided in Figure 2.

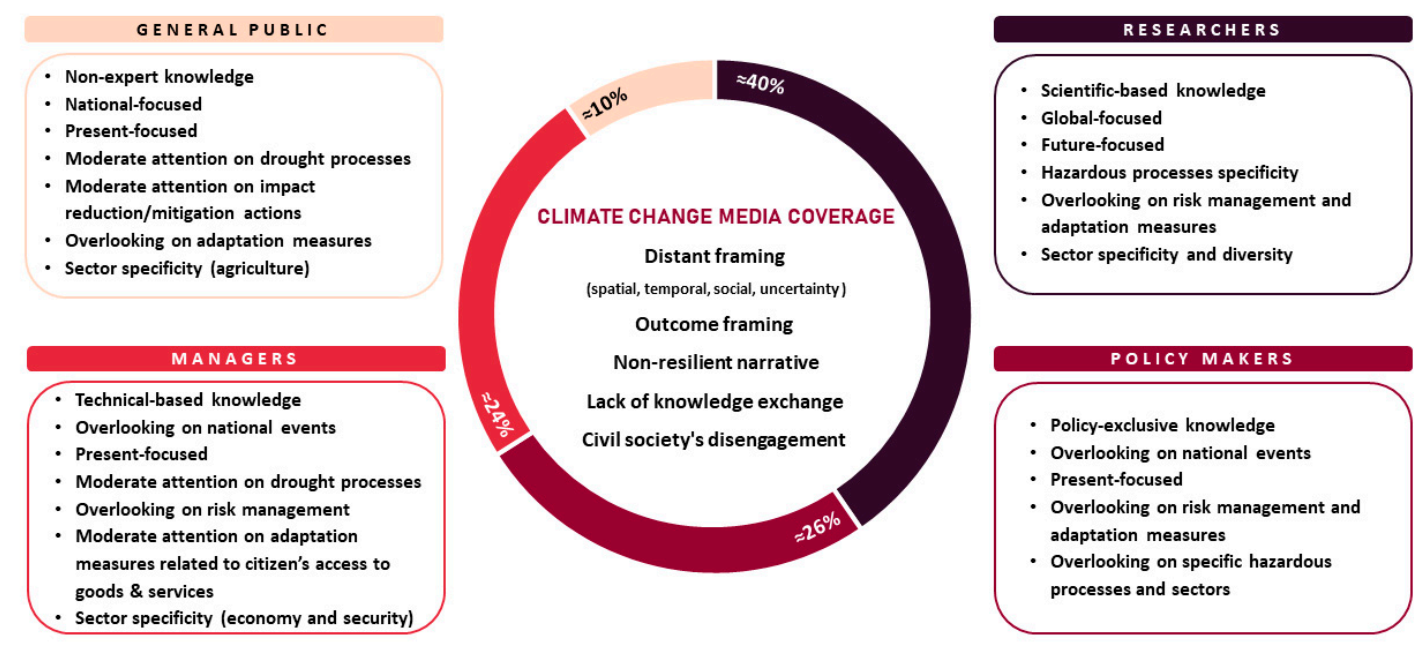

Figure 2. Conceptualization of the European media's discourses on climate change.

The results of our study demonstrate that the media still tend to privilege an environmental hyperopia narrative $[15,22]$, by reporting climate change as a spatial and temporal distant issue, that is more likely to occur in a distant future (e.g., in 10 to 50 years) and in the most vulnerable countries and/or communities (e.g., African countries, Pacific islands). Some examples found on the analyzed news' articles account for the global water shortage expected by 2050 being more likely to affect South America, Africa, and Australia [23]; the expected climate-induced refugee crisis expected for the next decade being more likely to affect the Middle East and North Africa [24]; or the 2017 world scientists' warning to humanity [25] in which some of the global results of climate change are highlighted (e.g., increased number of oceans' dead zones, loss of millions of acres of forest). These forms of reporting environmental issues are known to increase the individuals' psychological distance from climate change [26]; that is, the distance at which climate change consequences are perceived to occur, in its four dimensions [27]: spatial (likely to occur in far distant countries), temporal (likely to occur in a distant future), social (likely to occur to dissimilar others), and uncertainty (unlikely to occur in the news' country of origin). As it is well-established in the literature [28,29], the psychological distance represents a barrier of utmost importance to public engagement with climate change, by undermining the individuals' adoption of pro-environmental behaviors and actions to both mitigate and adapt to the actual climate crisis [29]. On the other hand, contrary to the media communication praxis, an effective form of communicating climate change would be by taking the problem here and now [30], by facilitating the psychological closeness to environmental issues on lay audiences. As recently found by Wang et al. (2019) [29], psychological closeness to climate change is strongly related with more engagement to environmental issues and thus with the individuals' adoption of pro-environmental behaviors. Taking this evidence into account, framing climate change in ways that feel relevant and psychologically close to the audiences would enhance the development of concrete emotions in the public (e.g., concern, guilt), which have been proven to be related to 
greater engagement with climate change, adoption of mitigation practices, and environmental policy support $[29,31,32]$.

It was also possible to ascertain that the European press tends to use the outcome framing, specially focused upon loss, in climate change media coverage. For instance, it was found on the analyzed news' articles a significant salience given to the increased suicide rates related to climate change in India [33]; to the prediction of an increase in about $48 \%$ of human deaths due to heatwaves in 2100 [34]; or to the only $5 \%$ chance of achieving the $2{ }^{\circ} \mathrm{C}$ increase above pre-industrial levels by 2100 , as established in the Paris Agreement [35]. These kinds of threatening climate change messages may be successful at evoking fear in the audiences, which was thought to be a useful motivational tool, as fear predicts action mobilization action towards oneself protection from harm [36]. However, the fear's effect, without an efficacy component, in triggering climate action has been widely questionable by scholars [21,37]. Indeed, research in the field has been constantly showing that loss-/threat-framed messages tends to lead to maladaptive message responses, such as psychological reactance, source denigration, and problem minimization [21,37-40]. In turn, these maladaptive responses undermine individuals' engagement to climate [37]. Alternatively, Nabi et al. (2018) [37] suggest that a communication form aiming to produce an emotional responses shift, specifically through the combination of negative and positive emotions, would be more effective in prompting individuals' climate action. For instance, the authors argue that combining simultaneously fear- and hope-inducing messages enhance the effectiveness of climate change messaging, considering that fear (e.g., threatening outcome) may be useful to enhance awareness, whereas hope (e.g., self-efficacy information) may be suitable to generate proactive behaviors. Other authors suggest that gain-framed and/or solution-focused messages have proven to be effective in developing positive attitudes towards climate change mitigation and thus in promoting an active engagement with the problem [11,21]. Despite this evidence, the analyzed media coverage still privilege non-resilient discourses, as it hardly gives salience to hope-inducing messages, climate success stories, or focus on concrete solutions, particularly risk management actions and adaptation measures.

Regarding actors' discourses, it was verified that within the climate change debate, more salience is given by far to researchers $(\approx 40 \%)$ that, following the aforementioned tendency, is generally distant-framed and non-proactive. Following scholars' discourses, more than a quarter of the analyzed news articles privilege the policymakers' narratives that, according to a further detailed analysis, demonstrated a correlation with North American events, particularly Donald Trump's environmental policy and the USA's withdrawal from the Paris Climate Accord [41]. The disproportionate attention given to contrarians or the skeptical, leaves the audience susceptible to an increased confusion regarding climate change and thus the public's widespread environmental alienation. As such, it is argued that editors should adjust the disproportionate attention given to these figures and to conflicting debates [42]. Yet, regarding actors' discourses and similar to findings of previous studies [7], the discourse of general public/users is barely reported in the European media. This result was, somewhat, unexpected, considering that the impact and adaptation to climate change should go beyond the scientific and political fields as "it transforms realities previously perceived as private and apolitical (... ) into contentious options of collective significance" [43] (p. 173). Despite collective significance of climate change, the actual panorama of communicating the problem demonstrates that the media tends to dismiss the common citizens from the climate change challenge, making it an exclusively institutionalized problem in which scientific, political, and technological narratives are considerably privileged. It is also worth mentioning that, as it is reported in the European media, the co-definition of societally relevant problems, the co-production or co-creation of relevant knowledge, and the co-learning from different actors' experiences [44] tend not to occur. Indeed, understanding and addressing climate change appears to be developed within actors' arena of knowledge, which was translated by a single-disciplinary form of communicating the climate [44]; this is without emphasis to the dialogue between each fields of expertise. For instance, environmental policy making was barely reported as empirical-based and vice-versa. 
To summarize, in terms of climate change the European press makes great use of distant and outcome framings, particularly focused upon loss, without giving a proportional salience to resilient actions, such as risk management and/or climate change adaptation measures. European press privileges the academic debate that is fundamentally future-framed and non-proactive. A detailed analysis of each actor's discourses demonstrates that there is not a knowledge exchange between actors, rather privileged sources within their own field of expertise. Finally, the common citizen is largely unseen in the European climate change media coverage, leaving the general society excluded from the climate change debate. Contrarily to the apparent communication praxis, it is argued that media communication on climate change may be more effective in engaging individuals to environmental matters, if it narrows the challenge of climate challenge to the audiences' context, making climate change a present and personally relevant issue. Additionally, more salience to solution-focused messages and climate success stories may increase individuals' self-efficacy and thus willingness to act. Finally, media communication should avoid controversial debates, whilst giving more salience to society's fundamental role in adapting to climate change.

The aforementioned conclusions and insights are limited in several ways. First, the study was limited to a short time frame ( 2 years) and to European countries. Future studies should enlarge both the time frame and geographical focus. Although the authors involved in data collection (N.P.A.; S.M.; J.J.) made an effort to prevent the selection of biased news' pieces, by using an incognito browser, the collected data might still have been slightly biased due to Google®filtering algorithms. Future studies should consider analysis using big data techniques to avoid the risk of filtering-related bias. Moreover, a quantitative content analysis, based on pre-determined variables, was the single method of this data analysis. Further studies would benefit from a mix-method analysis, considering qualitative methods to ascertain in-depth other news characteristics that are not identifiable through quantitative data analysis' strategies. Finally, the effect of the European framing on individuals' attitude regarding climate change was not tested in this study. Future social research should consider the exact communication strategies that actually seem to influence individuals' narratives and behaviors shaping.

Despite the aforementioned limitations, this study is of significant relevance, considering its' cross-national design, by analyzing the climate change media coverage of five southern and northern European countries, through a large sample of more than a thousand news articles. In addition, it was possible to determine the main weaknesses of European media coverage in order to suggest alternative evidence-based forms for communicating climate change with more efficacy and thus heightening the mediator effect of media on promoting society's climate action and adoption of new and sustainable new practices.

\section{Conclusions}

The European media coverage on climate change gives a disproportionate salience to distant climate-related events, based on threatening narratives, without a proportional attention to climate change solutions. These forms of reporting climate change may contribute to individuals' alienation or reactance regarding the climate crisis, in effect hindering citizens from adopting new, sustainable practices and supporting environmental policies.

Supplementary Materials: The following are available online at http://www.mdpi.com/2071-1050/12/20/8300/s1.

Author Contributions: Conceptualization, A.O.T. and N.P.A.; data selection, N.P.A., S.M., and J.J.; data curation: N.P.A; formal analysis, N.P.A.; funding acquisition, J.-F.B.; investigation, N.P.A., S.M., and J.J.; methodology, A.O.T., and N.P.A; validation, A.O.T.; writing-original draft, A.O.T., N.P.A., and D.S.I.; writing-review and editing, A.O.T., N.P.A, S.M., D.S.I., and L.B.C. All authors have read and agreed to the published version of the manuscript.

Funding: This study is part of the project "Risk-AquaSoil - Atlantic Risk Management Plan in water and soil", co-financed by the European Regional Development Fund (ERDF) through the INTERREG Atlantic Area Programme, reference EAPA_272/2016.

Conflicts of Interest: The authors declare no conflict of interest. 


\section{References}

1. Romps, D.M.; Retzinger, J.P. Climate news articles lack basic climate science. Environ. Res. Commun. 2019, 1, 081002. [CrossRef]

2. Moser, S.C. Communicating climate change: History, challenges, process and future directions. Wiley Interdiscip. Rev. Clim. Chang. 2009, 1, 31-53. [CrossRef]

3. Sequeira, M.; Castilho, A.; Tavares, A.; Dinis, P. Assessment of superficial water quality of small catchment basins affected by Portuguese rural fires of 2017. Ecol. Indic. 2020, 111, 105961. [CrossRef]

4. O'Brien, K.; Selboe, E.; Hayward, B.M. Exploring youth activism on climate change: Dutiful, disruptive, and dangerous dissent. Ecol. Soc. 2018, 23. [CrossRef]

5. Roser-Renouf, C.; Maibach, E.W.; Leiserowitz, A.; Zhao, X. The genesis of climate change activism: From key beliefs to political action. Clim. Chang. 2014, 125, 163-178. [CrossRef]

6. Plein, C. Resilience, Adaptation, and Inertia: Lessons from Disaster Recovery in a Time of Climate Change. Soc. Sci. Q. 2019, 100, 2530-2541. [CrossRef]

7. Areia, N.P.; Intrigliolo, D.S.; Tavares, A.; Mendes, J.M.; Sequeira, M.D. The role of media between expert and lay knowledge: A study of Iberian media coverage on climate change. Sci. Total Environ. 2019, 682, 291-300. [CrossRef]

8. Boykoff, M.T.; Rajan, S.R. Signals and noise. EMBO Rep. 2007, 8, 207-211. [CrossRef]

9. Wonneberger, A.; Meijers, M.H.; Schuck, A.R. Shifting public engagement: How media coverage of climate change conferences affects climate change audience segments. Public Underst. Sci. 2019, in press. [CrossRef]

10. Shehata, A.; Hopmann, D.N. Framing climate change: A study of US and Swedish press coverage of global warming. J. Stud. 2012, 13, 175-192. [CrossRef]

11. Stecula, D.A.; Merkley, E. Framing climate change: Economics, ideology, and uncertainty in American news media content from 1988 to 2014. Front. Commun. 2019, 4. [CrossRef]

12. Boykoff, M.T.; Boykoff, J.M. Climate change and journalistic norms: A case-study of US mass-media coverage. Geoforum 2007, 38, 1190-1204. [CrossRef]

13. De Vries, G.; Terwel, B.W.; Ellemers, N. Perceptions of manipulation and judgments of illegitimacy: Pitfalls in the use of emphasis framing when communicating about $\mathrm{CO}_{2}$ Capture and storage. Environ. Commun. 2015, 10, 206-226. [CrossRef]

14. Lopera, E.; Moreno, C. The uncertainties of climate change in Spanish daily newspapers: Content analysis of press coverage from 2000 to 2010. J. Sci. Commun. 2014, 13. [CrossRef]

15. Uzzell, D.L. The psycho-spatial dimension of global environmental problems. J. Environ. Psychol. 2000, 20, 307-318. [CrossRef]

16. Metag, J. Content analysis in climate change communication. Oxf. Res. Encycl. Clim. Sci. 2016. [CrossRef]

17. Riffe, D.; Lacy, S.; Fico, F. Analyzing Media Messages: Using Quantitative Content Analysis in Research; Routledge: New York, NY, USA, 2014.

18. Dotson, D.M.; Jacobson, S.K.; Kaid, L.L.; Carlton, J.S. Media coverage of climate change in Chile: A content analysis of conservative and liberal newspapers. Environ. Commun. 2012, 6, 64-81. [CrossRef]

19. Anaafo, D. Between science and local knowledge: Improving the communication of climate change to rural agriculturists in the Bolgatanga Municipality, Ghana. Local Environ. 2019, 24, 201-215. [CrossRef]

20. Fox, E.; Rau, H. Disengaging citizens? Climate change communication and public receptivity. Ir. Political Stud. 2017, 32, 224-246. [CrossRef]

21. Spence, A.; Pidgeon, N. Framing and communicating climate change: The effects of distance and outcome frame manipulations. Glob. Environ. Chang. 2010, 20, 656-667. [CrossRef]

22. García-Mira, R.; Eulogio Real, J.; Romay, J. Temporal and spatial dimensions in the perception of environmental problems: An investigation of the concept of environmental hyperopia. Int. J. Psychol. 2005, 40, 5-10. [CrossRef]

23. UN. Sdg 6 Synthesis Report 2018 on Water and Sanitation; United Nations Publications: New York, NY, USA, 2018.

24. EJF. Our Changing Climate - Its Role in Conflict and Displacement; Environmental Justice Foundation: London, UK, 2017.

25. Ripple, W.J.; Wolf, C.; Newsome, T.M.; Galetti, M.; Alamgir, M.; Crist, E.; Mahmoud, M.I.; Laurance, W.F. World scientists' warning to humanity: A second notice. BioScience 2017, 67, 1026-1028. [CrossRef] 
26. Van der Linden, S.; Maibach, E.; Leiserowitz, A. Improving public engagement with climate change. Perspect. Psychol. Sci. 2015, 10, 758-763. [CrossRef]

27. Schuldt, J.P.; Rickard, L.N.; Yang, Z.J. Does reduced psychological distance increase climate engagement? On the limits of localizing climate change. J. Environ. Psychol. 2018, 55, 147-153. [CrossRef]

28. Gifford, R. The dragons of inaction: Psychological barriers that limit climate change mitigation and adaptation. Am. Psychol. 2011, 66, 290-302. [CrossRef]

29. Wang, S.; Hurlstone, M.J.; Leviston, Z.; Walker, I.; Lawrence, C. Climate change from a distance: An analysis of construal level and psychological distance from climate change. Front. Psychol. 2019, 10. [CrossRef]

30. Chu, H.; Yang, J.Z. Taking climate change here and now-mitigating ideological polarization with psychological distance. Glob. Environ. Chang. 2018, 53, 174-181. [CrossRef]

31. Chu, H.; Yang, J.Z. Emotion and the psychological distance of climate change. Sci. Commun. 2019, 41, 761-789. [CrossRef]

32. Jones, C.; Hine, D.W.; Marks, A.D. The Future is now: Reducing Psychological Distance to Increase Public Engagement with Climate Change. Risk Anal. 2016, 37, 331-341. [CrossRef]

33. Carleton, T.A. Crop-damaging temperatures increase suicide rates in India. Proc. Natl. Acad. Sci. USA 2017, 114, 8746-8751. [CrossRef]

34. Mora, C.; Dousset, B.; Caldwell, I.R.; Powell, F.E.; Geronimo, R.C.; Bielecki, C.R.; Counsell, C.W.W.; Dietrich, B.S.; Johnston, E.T.; Louis, L.V.; et al. Global risk of deadly heat. Nat. Clim. Chang. 2017, 7, 501-506. [CrossRef]

35. Raftery, A.E.; Zimmer, A.; Frierson, D.M.; Startz, R.; Liu, P. Less than $2{ }^{\circ} \mathrm{C}$ warming by 2100 unlikely. Nat. Clim. Chang. 2017, 7, 637-641. [CrossRef] [PubMed]

36. Lazarus, R.S. Stress and Emotion: A New Synthesis; Springer Publishing Company: Berlin/Heidelberg, Germany, 2006.

37. Nabi, R.L.; Gustafson, A.; Jensen, R. Framing climate change: Exploring the role of emotion in generating advocacy behavior. Sci. Commun. 2018, 40, 442-468. [CrossRef]

38. Cho, H.; Sands, L. Gain- and loss-frame sun safety messages and psychological reactance of adolescents. Commun. Res. Rep. 2011, 28, 308-317. [CrossRef]

39. Morton, T.A.; Rabinovich, A.; Marshall, D.; Bretschneider, P. The future that may (or may not) come: How framing changes responses to uncertainty in climate change communications. Glob. Environ. Chang. 2011, 21, 103-109. [CrossRef]

40. Quick, B.L.; Kam, J.A.; Morgan, S.E.; Montero Liberona, C.A.; Smith, R.A. Prospect theory, discrete emotions, and freedom threats: An extension of psychological reactance theory. J. Commun. 2014, 65, 40-61. [CrossRef]

41. Betsill, M.M. Trump's Paris withdrawal and the reconfiguration of global climate change governance. Chin. J. Popul. Resour. Environ. 2017, 15, 189-191. [CrossRef]

42. Petersen, A.M.; Vincent, E.M.; Westerling, A.L. Discrepancy in scientific authority and media visibility of climate change scientists and contrarians. Nat. Commun. 2019, 10, 3502. [CrossRef]

43. Carvalho, A. Media(ted) discourses and climate change: A focus on political subjectivity and (dis)engagement. Wiley Interdiscip. Rev. Clim. Chang. 2010, 1, 172-179. [CrossRef]

44. Swart, R.; Biesbroek, R.; Lourenço, T. Science of adaptation to climate change and science for adaptation. Front. Environ. Sci. 2014, 2, 1-8. [CrossRef]

(C) 2020 by the authors. Licensee MDPI, Basel, Switzerland. This article is an open access article distributed under the terms and conditions of the Creative Commons Attribution (CC BY) license (http://creativecommons.org/licenses/by/4.0/). 